\title{
UK consumer perceptions of meat
}

\author{
BY N. J. RICHARDSON \\ Institute of Food Research, Earley Gate, Whiteknights Road, Reading RG6 $2 E F$
}

Those avoiding red meat represent up to $16 \%$ of the UK population whilst the proportion of the UK claiming to be 'eating less meat' ranges from 32.5 to $48 \%$ (Woodward, 1988; Food Research Association, 1989; The Realeat Survey Office, 1990; Vegetarian Society, 1991). In contrast, total meat production has not varied dramatically over recent years. Production figures reveal that although there has been a decline in the consumption of lamb and beef, pork and poultry have increased in popularity resulting in a relatively constant figure for total meat intake in the UK (Meat and Livestock Commission, 1988-1992). The stability in meat consumption estimated from production figures and the decline in meat popularity apparent from recent studies could be attributed to a change in the types of meats consumed. Changes in diet calculated from current and retrospective data show that people are increasing their consumption of fish, chicken, lamb and shellfish but decreasing consumption of beef, meat products, offal and pork (Richardson et al. 1993). The present paper will provide evidence that consumer perceptions of meat are shifting in a complex pattern leading to the current changes in meat-eating. Predictions of future changes in the food market and the impact that these developments might have on meat consumption will be discussed.

\section{DEFINITIONS}

To investigate this complex area of food choice, the terms used to identify the foods (i.e. meat) and the eating habits (e.g. vegetarianism, 'meat'-eater) must be well defined. Researchers in the area of vegetarianism and reduced meat-eating have taken one of two approaches to define these terms. The most usual is to specify precise meanings for the terms so advising subjects what should be considered 'meat' and whether their habits qualify as 'vegetarian'. Although this approach offers the advantage of exact criteria it risks alienating or erroneously discounting consumers who do not fit these arbitrary criteria. A second option is to accept self-definitions, which implies less precise intake measurements, but might more faithfully reflect individual beliefs. However, the foods eaten, the categories that both the foods (for example, meat, non-meat) and diets are grouped under all need to be identified in order to investigate the motives and constructs in this area of diet choice. In a recent survey $63 \%$ of 'vegetarians' ate no meat or fish, but others were replacing red meat with fish and eggs (Safeway, 1991). Another survey found that half the adults who classified themselves as vegetarians ate some kind of meat (Woodward, 1988), suggesting an ambiguity in the use of these terms.

A questionnaire survey of the UK general population ( $n$ 1046) and members of the UK Vegetarian Society ( $n$ 387; Richardson et al. 1994b) found that many of the $15 \%$ of the population sample who classified themselves as 'demi' vegetarians ate some kind of meat on a regular basis and a number of those who stated that they were currently reducing their meat consumption had increased consumption of chicken and fish. Definition of the term 'meat' was compared across the two samples with a clear hierarchy of animal- 
derived foods described as meat by the general population sample. The food most often perceived to be meat was beef followed by lamb, pork, bacon, chicken, and then, included in this category by only half the respondents were offal, burgers and sausages (Richardson et al. 1994b). In the same study a much more inclusive array of 'meats' were listed by members of the Vegetarian Society.

It has been hypothesized that the foods considered to be the most 'meat-like' would be those ones which were avoided first when people become vegetarian (Beardsworth \& Keil, 1991a; Fiddes, 1991). There is clearly a relationship between dietary habits, that is vegetarian or meat-eater, and an individual's perception of foods. In the case of meat, perceptions could be distorted to allow a 'vegetarian' or 'reduced meat-eater' to have a clear conscience when consuming animal-derived foods that he/she does not consider to be meat.

\section{ATTITUDES}

The decision to buy and eat meat is a direct result of how meat is perceived by the consumer. Not eating meat may result from a vegetarian considering it to be a 'non-food', a person who is keeping to a strict budget might perceive meat as too expensive whilst meat to a dieter could be thought of as energy laden; on the other hand a meat consumer might perceive meat to be nutritious, tasty or even a treat for special occasions (Nicod, 1980; Watson, 1980). The same product, therefore, can be associated with different attitudes across individuals. The attitudes associated with meat have changed rather dramatically over the past 50 years reflecting economic, social and demographic shifts (Breidenstein, 1988); in the 1940s and 1950s price, availability and quality were the main factors influencing meat purchase whereas present day issues include convenience, ethics, nutrition, ecology, use of additives/hormones/antibiotics, cholesterol elevation and risk of food poisoning. The influence that these factors will have on purchase decisions is far from universal.

In a recent study (Richardson et al. 1994a), attitudes on an array of meat-related issues were compared across those people who had either increased or decreased consumption of a number of meats and non-meats over the preceding year. Those who had increased consumption of chicken, pulses, milk, and meat substitutes held a stronger attitude towards health than those who had decreased consumption. Increases in the consumption of shellfish and pulses were related to a higher concern about the hormone, cholesterol and additive contents of foods. The majority of vegetarians ( $81 \%)$ as well as those considering becoming vegetarians or reducing meat consumption cite concerns about animal suffering as a major determinant of their choice of diet (British Nutrition Foundation, 1988; Woodward, 1988; Vegetarian Society, 1991). Animal cruelty was an important issue for a sample of UK adults in the consumption of some meats (pork, chicken, lamb, beef, offal) but not others (meat products, fish or shellfish) and was also important for eggs (Richardson et al. 1993).

The attitude of family, friends, and other individuals in positions of power or influence may be important in assisting or resisting changing habits (Freeland-Graves et al. 1986; Kerr \& Charles, 1986). In contrast, a trend towards the consumption of lighter, more informal meals may have an effect on meat demand since such meals (pasta, salads, sandwiches, etc) are frequently meat-free. 


\section{TASTE}

Taste ranks highest in terms of self-rated importance in food choice decisions (Schutz et al. 1986) and in studies of correlations between beliefs, attitudes and food choice (Krondl \& Lau, 1982; Shepherd, 1990). Multiple regressions of attitudes (belief $\times$ evaluation scores; Fishbein \& Ajzen, 1975) held by adult ( $>18$ years) members of the UK population against present consumption of the foods revealed that taste was a significant determinant in consumption of all of the thirteen foods studied (i.e. eggs, pork, cheese, chicken, meat substitutes defined as quorn and textured vegetable protein, lamb, pulses, beef, milk, offal of which liver and kidney were examples, meat products, fish and shellfish; Richardson et al. 1993). A difference in the perceived importance of taste was found between those who had changed their consumption of beef, since those who had increased their consumption had a stronger attitude on this dimension (Richardson et al. 1993). This suggests that hedonic factors play an important role in beef consumption. Even a few established vegetarians or vegans express nostalgia for the flavour of meat, with curiously regular mention of the taste and smell of bacon in particular (Beardsworth \& Keil, 1991a; Fiddes, 1991). Although meat has traditionally been regarded as having a 'good' taste, dislike of its taste, sometimes to the extent of nausea, regularly figures in survey responses by those who avoid it. Related to a dislike of the taste of meat, is a feeling of repulsion at the idea of preparing or cooking animal flesh (British Nutrition Foundation, 1988; Woodward, 1988; Beardsworth \& Keil, 1991b).

\section{HEALTH}

Health benefits or risks are probably the most commonly acknowledged reason for reducing meat consumption after ethical concerns (Beardsworth \& Keil, 1991a). Comparisons showing vegetarians to be healthier than meat-eaters are potentially difficult to interpret since meat-avoiders may be more likely to be middle-class, leading healthier lifestyles (lower levels of smoking and alcohol intake) or to have adopted their diet for reasons of preventative health or due to illness (Freeland-Graves et al. 1986; British Nutrition Foundation, 1988; Dwyer, 1991; Harrington, 1992). Members of the UK Vegetarian Society were found to hold stronger attitudes than a UK population sample on ethical, risk and health issues, whilst both samples were concerned about foods seen as cholesterol-elevating and convenience foods (Richardson et al. 1994b). Vegetarians and, especially, vegans usually come closer to achieving the recommended dietary patterns regarding cholesterol and fat than do omnivores; vegans generally consume $<10 \%$ of their energy as saturated fats, although vegetarians may consume more, depending on their intake of dairy fat (Draper et al. 1990; Dwyer, 1991). It has, however, been argued that 'healthy' omnivorous diets may be equally beneficial in at least some cases (Lockie et al. 1985; Dwyer, 1991).

\section{INFORMATION ON MEAT}

Attitudes and, therefore, behaviour choices are not only based on personal experience but also on information acquired through various media. Food package labels, magazines, newspapers, books, pamphlets, family, friends, doctors, health professionals, TV programmes and commercials have been found to be important in the acquisition of 
nutrition information (Feick et al. 1986; Bender \& Derby, 1992). The credibility of sources for meat-related information is dependent on both the characteristics of the individual (e.g. vegetarian or meat-eater) and the perceived vested interest of the source. Information on meat found in publications from the Vegetarian Society was more highly trusted by its members than by the general population who trusted government leaflets and the Meat and Livestock Commission (Richardson et al. 1994b) more highly. Food package labels were found to be highly trusted by both samples questioned in this study suggesting that labels are an influential source of meat-related information on both ethical and nutritional topics.

Meat-promoting and educational bodies in both the UK (Meat and Livestock Commission and Health Education Authority, 1990) and the US (National Livestock and Meat Board, 1993) suggest that an increase in the accuracy of scientific information that is relayed to consumers will increase the rationality of consumers' food choices and lead to the adoption of healthier diets. The source used to relay such information could greatly affect the way that any new findings are received by the general public. The source most likely to be believed for information concerning the benefits of technological advances in food production in the UK was the Consumers' Association and the least likely were government ministers (Sparks et al. 1992). The success of technological advances such as biotechnology will be hampered if the public perceives the resultant product changes as increasing animal exploitation and unnatural manipulation (Harrington, 1992) even though it is, when performed within species, an accelerated form of conventional genetic selection. Developments such as these suggest that new research techniques could change people's perceptions of meats as the products themselves are altered to allay consumer concerns.

\section{FUTURE PREDICTIONS}

There is no doubt that consumer perceptions of meat are shifting in a complex pattern reflecting a wide array of purchase criteria. The proportion of vegetarians in the UK and the USA remains below $5 \%$ yet there is much evidence for a trend away from the red meats of beef and lamb towards the increasingly popular white meats (e.g. poultry, pork and fish). If people do in fact avoid meats in a hierarchical order, starting with red meats followed by white meats until dairy products are the only animal-derived foods consumed then this recently found change in diets could be the first step to an eventual vegetarian plurality. Such a trend could be enhanced by the proliferation of more conventional non-meat products so that this food style will be seen as less eccentric as it becomes more widespread (Beardsworth \& Keil, 1993).

If people are avoiding red meat for the reasons of perceived unhealthiness, high prices or convenience then a change in any one could reverse the current trend. Certainly, convenience does play a role in influencing the types and cuts of meats purchased (Anderson \& Shugan, 1991). 'Cook-chill' products boast the highest levels of convenience yet often contain minimal amounts of meat as this is often the most expensive ingredient. Frequent use of such pre-prepared products could result in reductions in meat consumed by individuals who are not consciously reducing meat in their diets.

It has been argued that changes in future meat consumption will result from the elimination or reduction of risk factors such as saturated fat, bovine spongiform encephalopathy and salmonella (Wheelock, 1989). A scenario technique has been used 
to test the effects of future changes in price and availability of both 'polyunsaturated' (meat containing a high proportion of fat in the polyunsaturated form) and 'microorganism-free' meat (this was defined in the questionnaire as meat which had all harmful micro-organisms eliminated from it during production) on predicted consumption (Richardson et al. 1993). It was found that polyunsaturated meat would be eaten in preference to 'normal' meat if the price was held constant, however, if an increase in price was associated with this intervention then it was predicted that they would not buy this healthier meat. The elimination of micro-organisms from meat was a safeguard for which the majority were prepared to pay extra. Indeed, consumer concerns of the presence of chemicals and steroids in meat have been found to dominate those of price, quality and uncertainty of the fat content (Shearer et al. 1986). The finding that people are more concerned about and willing to pay extra for safeguards against hazardous substances in meat but not for polyunsaturated meat may illustrate the potential differences in perceived risks from different sources (P. Sparks and R. Shepherd, unpublished results).

\section{CONCLUSIONS}

It is clear from recent studies that vegetarianism and meat-eating should not be thought of as mutually exclusive diet categories but as either end of an eating dimension. The point at which an individual will position him/herself along this dimension will depend both on his/her diet and on the foods that he/she considers to be meat. The diet that an individual chooses will reflect that person's purchase criteria but not in a uniform way. Consumer perceptions of meat determine meat consumption in a demand-driven market (e.g. that of the UK and USA). Perceptions are based on personal experience, the experience of friends and relatives, the media's portrayal of different issues, advertising and even propaganda in this emotive area. The choice to avoid meat can change the entire structure of a person's eating habits and is thought to reflect on a whole new philosophy of life (Amato \& Partridge, 1989), whilst the consumption of meat represents those who, at present, do not differ from the status quo. If the current increase in 'reduced meat-eaters' does represent a sea-change then a meat-eating ideology might evolve with a whole new set of attitudes and related issues which defend the eating of meat. Future research should be mindful of these shifting attitudes and perceptions and not just changes in diet.

The author would like to thank Dr R. Shepherd for his helpful comments on this paper and the Ministry of Agriculture, Fisheries and Food for financial support.

\section{REFERENCES}

Amato, P. R. \& Partridge, S. A. (1989). The New Vegetarians: Promoting Health and Protecting Life. New York: Plenum Press.

Anderson, E. W. \& Shugan, S. M. (1991). Repositioning for changing preferences: the case of beef versus poultry. Journal of Consumer Research 18, 219-232.

Beardsworth, A. D. \& Keil, E. T. (1991a). Vegetarianism, veganism and meat avoidance: recent trendś and findings. British Food Journal 93, 19-24.

Beardsworth, A. \& Keil, T. (1991b). Health-related beliefs and dietary practices among vegetarians and vegans: a qualitative study. Health Education Journal 1, 38-42. 
Beardsworth, A. D. \& Keil, E. T. (1993). Contemporary vegetarianism in the UK: challenge and incorporation? Appetite 20, 229-234.

Bender, M. M. \& Derby, B. M. (1992). Prevalence of reading nutrition and ingredient information on food labels among adult Americans. Journal of Nutrition Education 24, 292-297.

Breidenstein, B. C. (1988). Changes in consumer attitudes toward red meat and their effect on marketing strategy. Food Technology 42, 112-116.

British Nutrition Foundation (1988). Vegetarian Diets. London: British Nutrition Foundation.

Draper, A., Wheeler, E. F. \& Lewis, J. (1990). What do 'vegetarians' eat? Proceedings of the Nutrition Society 49, 60A.

Dwyer, J. T. (1991). Nutritional consequences of vegetarianism. Annual Review of Nutrition 11, 61-91.

Feick, L. F., Hermann, R. O. \& Warland, R. H. (1986). Search for nutrition information: a probit analysis of the use of different information sources. Journal of Consumer Affairs 20, 173-192.

Fiddes, N. (1991). Meat: A Natural Symbol. London: Routledge.

Fishbein, M. \& Ajzen, I. (1975). Belief, Attitude, Intention and Behavior: an Introduction to Theory and Research. Massachusetts: Addison-Wesley.

Freeland-Graves, J., Greninger, S. \& Young, R. (1986). A demographic and social profile of age- and sex-matched vegetarians and non-vegetarians. Journal of the American Dietetic Association 86, 907-981.

Food Research Association (1989). Vegetarianism and the Consumer. Leatherhead Survey Contents. Leatherhead, Surrey: Food Research Association.

Harrington, G. (1992). Development in consumer concerns about animal production in the 1980s and their influence on meat marketing and its regulation. Anthropos 16, 143-149.

Kerr, M. \& Charles, N. (1986). Servers and providers: the distribution of food within the family. Sociological Review 34, 115-157.

Krondl, M. \& Lau, D. (1982). Social determinants in human food selection. In The Psychobiology of Human Food Selection, pp. 139-151 [L. M. Barker, editor]. Connecticut: AVI.

Lockie, A. H., Carlson, E., Kipps, M. \& Thomson, J. (1985). Comparison of four types of diet using clinical, laboratory and psychological studies. Journal of the Royal College of General Practitioners 35, 333-336.

Meat and Livestock Commission (1988-1992). Meat Demand Trends. Milton Keynes: Meat and Livestock Commission and Health Education Authority.

Meat and Livestock Commission and Health Education Authority (1990). Meat Diet and Health: a Report on Red Meat Today. Milton Keynes: Meat and Livestock Commission and Health Education Authority.

National Livestock and Meat Board (1993). The Meat Consumer 1993: Demand Strategies. Chicago: National Livestock and Meat Board.

Nicod, M. (1980). Gastronomically speaking: Food Studied as a Medium of Communication. In Nutrition and Lifestyles, pp. 53-66 [M. Turner, editor]. London: Applied Science Publishers Ltd.

Richardson, N. J., MacFie, H. J. H. \& Shepherd, R. (1994a). Consumer attitudes to meat eating. Meat Science 36, 57-65.

Richardson, N. J., Shepherd, R. \& Elliman, N. A. (1993). Current attitudes and future influences on meat consumption in the UK. Appetite 21, 41-51.

Richardson, N. J., Shepherd, R. \& Elliman, N. A. (1994b). Meat consumption, definition of meat and trust in information sources in the UK population and members of The Vegetarian Society. Ecology of Food and Nutrition (In the Press).

Safeway (1991). Today's vegetarian shopper: a survey by Safeway into the reactions of vegetarians. Home Economist 6, 17-18.

Schutz, H. G., Judge, D. S. \& Gentry, J. (1986). The importance of nutrition, brand, cost and sensory attributes to food purchase and consumption. Food Technology 40, 79-82.

Shearer, G., Burgess, P. \& English, R. (1986). A study of consumer attitudes to fat in meat. Animal Production 42, 458.

Shepherd, R. (1990). Attitudes and beliefs as determinants in food choice. In Psychological Basis of Sensory Evaluation, pp. 141-161 (R. L. McBride and H. J. H. MacFie, editors]. London: Elsevier Applied Science.

Sparks, P., Shepherd, R. \& Frewer, L. J. (1992). The environment, the economy and the ethical: assessing dimensions of public attitudes towards the application of gene technology to food production. 6th European Health Psychology Society Conference, Leipzig. Health Psychology in a Changing Europe, p. 214.

The Realeat Survey Office (1990). The Realeat 1990 Survey into Meat-eating and Vegetarianism; Main Findings. London: The Realeat Survey Office.

Vegetarian Society (1991). The 1991 Food Survey - Trends in Vegetarianism Amongst Adults and Young People. Altrincham: The Vegetarian Society. 
Watson, R. (1980). Psychological influences on eating behaviour. In Nutrition and Lifestyles, pp. 43-52 [M. Turner, editor]. London: Applied Science Publishers Ltd.

Wheelock, V. (1989). Food safety in perspective. British Food Journal 91, 31-36.

Woodward, J. (1988). Consumer attitudes towards meat and meat products. British Food Journal 90, $101-104$. 